\title{
Update on current views and advances on RSV infection (Review)
}

\author{
IOANNIS N. MAMMAS ${ }^{1-3}$, SIMON B. DRYSDALE ${ }^{4,5}$, BARBARA RATH $^{6-8}$, MARIA THEODORIDOU $^{2}$, \\ GEORGIA PAPAIOANNOU ${ }^{9}$, ALEXIA PAPATHEODOROPOULOU ${ }^{10}$, EIRINI KOUTSOUNAKI ${ }^{11,12}$, \\ CHRYSSIE KOUTSAFTIKI ${ }^{13}$, ELEFTHERIA KOZANIDOU ${ }^{14}$, VASSILIS ACHTSIDIS ${ }^{15}$, \\ PARASKEVI KOROVESSI ${ }^{16}$, GEORGE P. CHROUSOS ${ }^{2}$ and DEMETRIOS A. SPANDIDOS ${ }^{1}$
}

${ }^{1}$ Laboratory of Clinical Virology, School of Medicine, University of Crete, 71003 Heraklion; ${ }^{2}$ First Department of Paediatrics, University of Athens School of Medicine, 11527 Athens; ${ }^{3}$ Paediatric Clinic, 34500 Aliveri, Greece; ${ }^{4}$ St. George's, University of London, London SW17 0RE; ${ }^{5}$ Department of Paediatric Infectious Diseases, St. George's University Hospitals NHS Foundation Trust, London SW17 0QT, UK; ${ }^{6}$ Vienna Vaccine Safety Initiative, D-10437 Berlin, Germany; ${ }^{7}$ Université Bourgogne Franche-Comté, 25000 Besancon, France; ${ }^{8}$ University of Nottingham School of Medicine, Nottingham NG7 2UH, UK; ${ }^{9}$ Department of Paediatric Radiology, 'Mitera' Children's Hospital, 15123 Athens; ${ }^{10}$ Paediatric Intensive Care Unit (PICU), 'Aglaia Kyriakou' Children's Hospital, 11527 Athens;

${ }^{11}$ Neonatal Department, 'Alexandra' Maternity Hospital, 15123 Athens; ${ }^{12}$ Neonatal Department, 'Helena Venizelou' Maternity Hospital, 11521 Athens; ${ }^{13}$ Paediatric Intensive Care Unit (PICU), 'Penteli' Children's Hospital, 15236 Penteli;

${ }^{14} 2$ nd Department of Internal Medicine, 'St Panteleimon' General Hospital of Nikaia, 18454 Piraeus, Greece;

${ }^{15}$ Department of Ophthalmology, Royal Cornwall Hospitals, Cornwall TR1 3LQ, UK;

${ }^{16}$ Department of Paediatrics, 'Penteli' Children's Hospital, 15236 Penteli, Greece

Received May 15, 2020; Accepted June 15, 2020

DOI: $10.3892 / \mathrm{ijmm} .2020 .4641$

\begin{abstract}
Respiratory syncytial virus (RSV) infection represents an excellent paradigm of precision medicine in modern paediatrics and several clinical trials are currently performed in the prevention and management of RSV infection. A new taxonomic terminology for RSV was recently adopted, while the diagnostic and omics techniques have revealed new modalities in the early identification of RSV infections and for better understanding of the disease pathogenesis. Coordinated clinical and research efforts constitute an important step in limiting RSV global predominance, improving epidemiological surveillance, and advancing neonatal and paediatric care. This review article presents the key messages of the plenary lectures, oral presentations and posters of the '5th workshop on paediatric virology' (Sparta, Greece, 12th October 2019) organized by the Paediatric Virology Study Group, focusing
\end{abstract}

Correspondence to: Professor Demetrios A. Spandidos, Laboratory of Clinical Virology, School of Medicine, University of Crete, 71003 Heraklion, Greece

E-mail: spandidos@spandidos.gr

Key words: Paediatric virology, respiratory syncytial virus, RSV, bronchiolitis, precision medicine, antivirals, prevention, vaccines, PEDSIDEA, disease severity, clinical outcomes, ViVI Score, imaging; taxonomy, epidemiology, neonatal immune response, microRNAs, thrombocytosis, asthma, bronchiolitis obliterans, high-flow nasal cannula, heliox, PICU on recent advances in the epidemiology, pathogenesis, diagnosis, prognosis, clinical management and prevention of RSV infection in childhood.

\section{Contents}

1. Introduction

2. Epidemiology of RSV infection

3. Pathogenesis, diagnosis and prognosis of RSV infection

4. Imaging in children with RSV infection

5. Therapeutics of RSV infection

6. Prevention of RSV infection

\section{Introduction}

Precision medicine has evolved in recent years allowing the incorporation of novel taxonomies and stratification of patients, and using standardized clinical endpoints, genetic and other biomarker information (1). Its role in paediatric healthcare involves the selection of targeted diagnostic, therapeutic and prevention strategies matched to precise molecular, epidemiological and clinical profile of each patient; the management of respiratory syncytial virus (RSV) infection represents a good paradigm of precision medicine (2). RSV is a single-stranded RNA virus (Figs. 1 and 2), which represents the most frequent viral cause of acute lower respiratory tract infection (ALRTI) in infants, with a worldwide distribution and seasonal occurrence (2-5). It was first isolated in 1956 from nasal secretions of chimpanzees with rhinorrhea and coryza; the novel virus was 
initially named 'Chimpanzee coryza agent' (CCA) (6,7). In the following year, when CCA was also isolated from children with ALRTI, it gained its final name due to the syncytia observed on electron microscopy; syncytia are formed by fusion of infected host cells with neighboring cells leading to the formation of multi-nucleate enlarged cells. Although the formation of syncytia is the hallmark of the cytopathic effect of RSV that is associated with host cellular membrane merging, syncytia are not pathognomonic of RSV (8). Syncytia are also observed in cell culture with several other viruses, such as parainfluenza, HSV-1, HIV and MeV. Recently, the International Committee on Taxonomy of Viruses (ICTV), which authorizes and organizes the classification and naming of viral species, grouped RSV under the genus Orthopneumovirus within the family Pneumoviridae $(9,10)$.

Bronchiolitis is the most common clinical manifestation of RSV infection in infants and although it is usually self-limiting, in infancy it accounts for a significant number of hospitalizations and paediatric intensive care unit (PICU) admissions (3). Despite its association with relatively high morbidity and mortality in premature neonates and in certain paediatric populations with underlying conditions, such as immunodeficiency and congenital heart disease, RSV infection may also lead to hospitalization of previously healthy, full-term infants $(11,12)$. RSV-positive bronchiolitis is characterized by airway inflammation and oedema, mucus production and debris leading to airway obstruction and turbulent gas flow. Even though various therapeutic interventions have been tried, such as bronchodilators, hypertonic saline and corticosteroids, supportive care remains the mainstay in most settings, with gentle suctioning of nasal secretions, prone position, fluid replacement and oxygen or respiratory support, as necessary. Several clinical trials on the management and prevention of RSV-positive bronchiolitis have been recently completed, are underway, or in development (3). Currently, there is rapid expansion of RSV vaccine candidate development and there is hope that one will become available in the near future. Of course, the safety of vaccines proposed for primary immunization in an antigen naïve child remains the top priority.

This review article summarizes the key messages of the plenary lectures, oral presentations and posters of the '5th Workshop on Paediatric Virology' held in Sparta (Greece) on October 12th, 2019, which was focused on RSV (Table I). This workshop was organized by the Paediatric Virology Study Group (PVSG) and was co-chaired by Dr Simon B. Drysdale, Consultant and Honorary Senior Lecturer in Paediatric Infectious Diseases at St. George's University Hospital NHS Foundation Trust and St. George's, University of London (London, UK), Professor Barbara Rath, Co-founder and Chair of the Vienna Vaccine Safety Initiative (Berlin, Germany), Honorary Professor of Nottingham School of Medicine (Nottingham, UK) and Research Director at the University of Bourgogne-Franche-Comté (Besançon, France), Professor Maria Theodoridou, Professor Emerita of Paediatrics at the University of Athens School of Medicine (Athens, Greece), President of the National Immunisation Committee and f. President of the Hellenic Paediatric Infectious Diseases Society, Dr Georgia Papaioannou, Head of the Paediatric Radiology Department at 'Mitera' Children's Hospital in Athens (Greece), Dr Ioannis N. Mammas, Consultant Paediatrician on the island of Euboea (Greece) and Coordinator of the PVSG and Professor George P. Chrousos, Professor Emeritus of Paediatrics and Endocrinology at the University of Athens School of Medicine (Athens, Greece). The workshop was held under the auspices of the World Academy of Sciences (WAS) and was supported by the Laboratory of Clinical Virology of the University of Crete School of Medicine and the First Department of Paediatrics of the University of Athens School of Medicine.

\section{Epidemiology of RSV infection}

Understanding the burden of RSV infections in real-time. RSV poses significant disease burden in infants and children worldwide (13), and the international paediatric community is only beginning to appreciate its global impact in both high and low resource settings $(4,14,15)$. The clinical presentation of an RSV infection depends on the patient's age and individual risk factors $(16,17)$. The concept of measuring individual-level differences in disease severity has drawn the attention of both public health stakeholders and regulatory agencies in recent years (18-20). The impact of RSV infections of course should be differentiated from the disease caused by influenza and other viral respiratory infections $(21,22)$. However, a recent extensive literature review and prospective cohort have shown that in infants and children this cannot be done based on clinical symptoms alone; distinguishing RSV from other viral respiratory infections requires laboratory confirmation $(23,24)$. With RSV vaccines and antiviral agents in development, it will be important to: a) diagnose RSV infections in a timely manner; b) differentiate RSV from other forms of acute respiratory infections; and c) communicate the test results back to patients and parents/caregivers along with information on the individual disease risk and severity.

The PEDSIDEA programme. The Vienna Vaccine Safety Initiative (ViVI, https://www.vi-vi.org) is an international non-profit research organization which, in collaboration with academic institutions and public health agencies in Europe and the United States, has developed digital tools and programs to improve the quality of care for children and adults with ALRTI or influenza-like illnesses (ILI) $(13,25,26)$. Taking a person-centered approach, the ViVI Disease Severity Score ('ViVI Score') is a mobile application enabling healthcare professionals to measure disease severity at the point of care within minutes. It was designed to provide a uniform approach to define ad hoc severity at any given time point, based on extensive literature review as well as WHO Criteria for uncomplicated and complicated ILI (27). In collaboration with the Robert Koch Institute, the ViVI Score was validated in a cohort of 6,000 children (age 0-18) in Berlin, Germany and subsequently used in a European pilot project entititled 'Partnering for Enhanced Digital Surveillance of Influenza-like Disease and the Effectiveness of Antivirals and Vaccines' (PEDSIDEA) $(27,28)$. Since then, the PEDSIDEA programme has been implemented in community clinic networks and adult intensive care units in the Unites States for the real-time digital surveillance of influenza and RSV disease incidence and severity at the point of care (29). The programme is expected to continue monitoring, in great detail, the clinical outcomes 


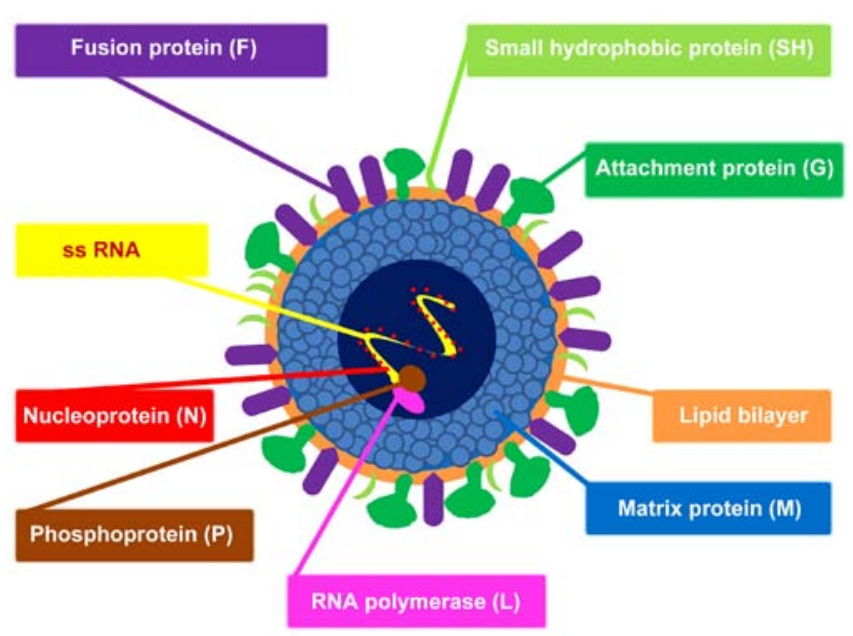

Figure 1. Schematic structure of RSV. The virus envelope contains the fusion protein $(\mathrm{F})$, the small hydrophobic protein $(\mathrm{SH})$ and the attachment protein (G). Underlying the envelope is the matrix protein (M). The nucleocapsid consists of single-stranded RNA (ss RNA) encapsulated by the nucleoprotein (N). Associated with the nucleocapsid are the RNA polymerase (L) and the phosphoprotein $(\mathrm{P})$. RSV, respiratory syncytial virus.

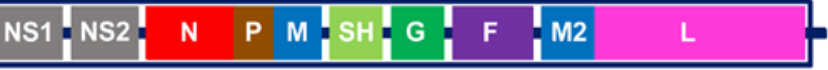

Figure 2. RSV genome organisation. Genes are listed in sense (coding) orientation ( 3 '-to-5') in which each box represents a gene encoding a separate mRNA for each protein. NS1 and NAS2, nonstructural proteins; N, nucleoprotein; $\mathrm{P}$, phosphoprotein; $\mathrm{M}$, matrix protein; $\mathrm{SH}$, small hydrophobic protein, G, attachment proteins; F, fusion protein; M2, second matrix protein; L, RNA polymerase; RSV, respiratory syncytial virus.

of 'natural' RSV and other viral respiratory infections in children and adults, including patients at the extremes of age. Understanding the real-world disease burden may help facilitate the study of the effectiveness of novel influenza and RSV antiviral agents and vaccines, once they become available (30).

RSV infection: not for children only. RSV was not recognized as a potentially serious problem in older adults until the 1970s, when outbreaks of the virus occurred in long-term care facilities for the elderly (31-33). Since then, additional studies in hospitalized adults have suggested that RSV may be an important cause of illness in adults. Molecular diagnostics suggest that RSV positive specimens are commonly identified in elderly and high-risk adults, in a frequency similar to that of seasonal influenza $(31,34)$. Even though a positive RSV respiratory panel does not equate pathogenesis, it has been suggested that RSV may account for as much as 10,000 deaths annually in the United States among individuals above the age of 65 years $(31-33,35)$. This, in addition to the morbidity in infants, has stimulated interest in RSV vaccines and antiviral agents. Additional natural history studies are needed to better understand the actual burden of RSV infection among the elderly and high-risk adults.

\section{Pathogenesis, diagnosis and prognosis of RSV infection}

The immune response to RSV infection. Maternal antibodies may be able to mitigate RSV disease severity in young infants (17,36-38). It is assumed that the transplacental passage of RSV-specific antibodies occurs predominately during the third trimester of pregnancy. High titers can potentially protect term infants up to four months of age (38). In premature infants, passive immunity may be 'compromised' (39), but still has a role to play. The degree to which breast feeding may also contribute to passive immunity and to priming of immune system is currently under investigation (40). Once infection is established, the innate immune system plays a dual role in lowering the viral load and in mounting a secondary immune response. Prematurity and other conditions that compromise the immune response may lead to reduced levels of antiviral cytokines, such as the interferons (41). In infants, reduced signaling by TLRs and altered antigen-presenting cell functions, including low interleukin (IL)-12 and enhanced IL-6 and IL-23 production, coupled with reduced activation of regulatory $\mathrm{T}$ cells, may result in an adaptive response that is skewed toward Th2 and Th17 and away from protective Th1 and CTL responses (42). The potential specific role(s) of certain pattern recognition receptors in humans has/ve been suggested by the fact that certain TLR missense mutations are associated to a phenotype with propensity to wheezing (43). Apart from the individual genetics (44), the stage of lung maturation among term and premature infants also impacts on the Th1 to Th2 switch. In the case of prematurity, the mucosa prior to alveolarization is being deluged with $\mathrm{Th} 2$ inflammatory responses, even in the earlier stages of bronchopulmonary dysplasia (45). Impaired Th1 activation, coupled with little or no B cell memory, and inhibition of antibody production by IFN $\gamma$, produces low-titer, low-affinity antibody (46). The result may be a poorly protective and dysregulated defense mechanism that leads to bronchiolitis in susceptible infants (43). Later, the host immune response is permanently oriented to the direction of wheezing exacerbations, specifically triggered by RSV (47).

MicroRNAs as potential bio-markers in RSV infection. MicroRNAs (miRNAs) are involved in post-transcriptional gene regulation and play significant roles in the maintenance of the airway epithelial barrier of the respiratory tract (48-56). miRNAs have been implicated in the modulation of antiviral defense mounted by host innate and adaptive immunity, involving not only immune effector and inflammatory cells, but also parenchymal cells (50). Respiratory viruses, including $\mathrm{RSV}$, attack, as a primary target, the epithelial cells of the respiratory tract causing an altered expression of distinct miRNAs in the airway cells. The human innate immune response inhibits RSV replication early after inoculation, mainly through the action of interferons (53). Multiple miRNAs are induced by infection in a cell-type-specific fashion (51). RSV appears to alter host cell gene expression also through regulation of expression of miRNAs related to the interferon response $(50,53)$. Abnormal expression of miRNAs has been detected in both peripheral blood cells and airway epithelial cells in RSV-infected infants (54). Understanding alterations in miRNA expression profiles and identifying miRNA target genes in relation to the pathogenesis of RSV may help clarify the mechanisms of virus-host interactions, and immune dysfunction leading to airway hyper-reactivity and chronic respiratory diseases, such as asthma $(49,50,53,54)$. There are several methods for the purification, quantification and 
Table I. The top key messages of the ' 5 th workshop on paediatric virology' on RSV infection in children.

Epidemiology of RSV infection

RSV and immune response

RSV and miRNAs

RSV and thrombocytosis

RSV and asthma

RSV as a cause of PIBO

Imaging of RSV infection

Antivirals against RSV

RSV and PICU

Prevention of RSV infection
Being able to compare severity over time and/or across cohorts is useful in hospital-based QI programmes but also in multi-centre networks, such as PEDSIDEA

Understanding the real-world disease burden caused by RSV will facilitate the study of the effectiveness of antivirals and vaccines, once they become available

Recent epidemiological data indicate that RSV infection is an important illness in elderly and high-risk adults, with a disease burden similar to that of non-pandemic influenza

Maternal RSV-specific antibodies transmitted transplacentally during the third trimester of pregnancy are related to RSV disease severity in young infants

A greater understanding of miRNAs may enable them to be used as biomarkers of severe RSV infection and as novel targets for treatment or prophylaxis of RSV infection

Thrombocytosis in RSV-positive bronchiolitis does not require routine prophylactic anti-platelet treatment or further investigations

There is compelling evidence that severe respiratory infection induced by RSV is associated with subsequent development of asthma later in childhood

Further understanding of the role of RSV in asthma pathogenesis will enable our understanding of the impact of future vaccines against RSV in asthma prevention

There are only few reports in the literature of children with PIBO secondary to RSV as a single infection

Further research is required in order to investigate the potential impact of RSV co-infection in the severity and worse outcome in children with PIBO

Although imaging cannot diagnose RSV infection, it is important to identify the possible pattern of viral disease, in order to avoid unnecessary administration of antibiotic therapy and predict possible late effects

Standard radiological techniques, including CT, are unable to distinguish between acute bronchiolitis caused by RSV versus that caused by other respiratory viruses

HRCT of the lungs may be required to assess possible bronchial thickening and remodeling, the development of bronchiectasis and air-trapping

Ribavirin is currently the only licensed antiviral medication used to treat RSV infection; it has very limited efficacy and multiple toxicities, which means its use is usually reserved for severely immunocompromised children

Due to ethical and technical constraints human challenge models are only undertaken in adults, but if a product is shown to be efficacious in this setting it allows a faster move to trials in children than traditional trials which often take much longer to do

A greater understanding of individual data in newly developed pharmaceutical agents against RSV will potentially lead to future personalized treatment regimens

HFNC might have a role as a rescue therapy for children with RSV-positive bronchiolitis admitted to PICU to reduce their requirement for high-cost intensive care

Heliox could be useful in addition to standard medical care in the management of children with RSV-positive bronchiolitis admitted to PICU

To date, there is only one product available for prevention of RSV infection, palivizumab, the mAb that has been shown to reduce hospital admission due to RSV infection in some high risk infants by up to $80 \%$

There are currently $43 \mathrm{RSV}$ vaccines in development; of these, 21 are in clinical trials in humans; 14 in Phase 1, five in Phase 2 and two in Phase 3, 12 vaccines are in trials in children, 4 in pregnant women and 10 in older adults

A possible route to licensure is currently being sought with the US FDA and European licensing agencies for a maternal RSV vaccine, bringing hope of a vaccine becoming available that could save the lives of countless young infants worldwide

RSV, respiratory syncytial virus; mAb, monoclonal antibody; FDA, Food and Drug Administration; QI, quality improvement, PEDSIDEA, Partnering for Enhanced Digital Surveillance of Influenza-like Disease and the Effectiveness of Antivirals and Vaccines; ALRTI, acute lower respiratory tract infection; ILI, influenza-like illness; CT, computed tomography; HRCT, high-resolution computed tomography; ICTV, International Committee on Taxonomy of Viruses; miRNAs, microRNAs; PIBO, post infectious bronchiolitis obliterans; PICU, Paediatric Intensive Care Unit; HFNC, high-flow nasal cannula. 
characterization of miRNA expression profiles in biofluids, whole blood samples and tissue samples obtained in in vivo studies (55). Further research on miRNAs is expected to clarify their value as biomarkers of RSV infections and their sequelae (i.e., recurrent wheezing and asthma).

Thrombocytosis and RSV infection. The most frequent causes of secondary thrombocytosis in childhood are acute respiratory tract infections (57-61). To date, several authors have reported significantly higher mean platelet counts in patients with RSV than in patients with other acute respiratory tract infections (61-64). Thrombocytosis is more likely to occur in younger patients, who have clinical manifestations of wheezing and dyspnoea $(62,64)$. Moreover, thrombocytosis has been suggested as an early marker of RSV infection (62). Excessive thrombocytosis has also been detected at an early stage in cases of RSV-positive bronchiolitis (65). It has been proposed that thrombocytotic patients have a more severe clinical course and longer duration of hospitalization and that the platelet count may be a useful clinical marker associated with ALRTI severity $(61,64,66,67)$. Conversely, other authors have found that platelet counts do not correlate with disease severity and clinical outcome $(68,69)$. Routine prophylactic anti-platelet treatment or further investigations are not necessary in children with RSV-positive bronchiolitis and thrombocytosis $(61,68,70)$.

$R S V$-positive bronchiolitis and asthma. There is compelling evidence that infants with severe RSV infection in the early months of life have a subsequent increased risk of developing recurrent wheezing and/or asthma, with a prevalence of up to $30 \%$ compared with non-RSV groups (71-75). Whether this association is causal has been the subject of considerable debate on the potential role of RSV infection in the pathogenesis of asthma as well as the impact of asthma predisposition (genetic, environmental exposure, etc.) on the clinical course of RSV infection. A recent large retrospective cohort analysis of Australian children born between 2000 and 2010 suggested that different subgroups of high risk children, who developed RSV disease within the first 2 years of life, continued to be at elevated risk of having a first asthma hospitalization beyond the age of 7 years (76). On the other hand, large epidemiological observational studies demonstrate that the vast majority of infants hospitalized for RSV bronchiolitis do not fit into an 'at-risk' group (atopy, family history, etc.), suggesting that viral or host factors not thought of as classical risk factors, may play a role in disease severity $(74,77)$. Prospective studies with RSV-immunoprophylaxis (e.g., palivizumab) suggest that long-term effects of RSV prophylaxis appear less efficacious in infants with a family history of atopy. In addition, palivizumab decreases parent-reported recurrent wheeze, however the incidence of physician-diagnosed asthma is similar (78). A recent single-blind, randomized, placebo-controlled trial showed that RSV prevention in otherwise healthy preterm infants, did not have a major effect on asthma or lung function at the age of 6 years (79).

Considering the above findings, perhaps a more appropriate conclusion would be that RSV infection is important in the mechanism of wheezing development, at least in the first few years of life (80). RSV possesses the ability to counteract host defense systems through complex mechanisms that facilitate viral replication. This significant increase in asthma frequency seems to be predominantly related to long-term changes in neuroimmune control of airway tone rather than to allergic sensitization. In contrast to RSV bronchiolitis, atopy has been clearly associated with childhood asthma development after RSV-induced early wheezing $(81,82)$. High-risk (parental atopy or asthma) birth cohort studies from Wisconsin, United States, and Australia have shown that young children suffering from RSV-induced wheezing episodes are at high risk of developing school-age asthma $(81,82)$. Further prospective, follow-up studies are needed to clarify individual and environmental factors that promote more severe viral illnesses and long-term adverse respiratory outcome of children hospitalized for severe RSV infection. Developing a greater understanding of the pathophysiological mechanisms through which RSV causes recurrent wheezing/asthma, will lead to an evidence-based prevention strategy and perhaps reduce the subsequent risk for asthma (71).

Predicting asthma following RSV-positive bronchiolitis. The biomarker CCL5 (previously known as RANTES, a $\beta$-chemoattractant for inflammatory cells including T-lymphocyte subsets), in the nasal epithelium during RSV bronchiolitis, is strongly predictive of physician-diagnosed asthma $(83,87)$. Furthermore, it has been suggested that prematurely born infants have a predisposition to RSV infection-related respiratory morbidity, including subsequent respiratory dysfunction $(44,85)$. Single-nucleotide polymorphisms in genes coding for IL-8, IL-19, IL-20, IL-13, mannose-binding lectin, IFNG and RANTES, have been associated with wheezing following RSV LRTI in term-born infants (85). The site of infection might be another important factor related to asthma risk, thus viral ALRTI in infancy indicates an increased risk of subsequent asthma, while gastrointestinal infections might be protective (86). Asthma after severe RSV bronchiolitis is positively correlated with maternal asthma, exposure to high levels of dog allergen, aeroallergen sensitization and recurrent wheezing; day care attendance and white race have been associated with decreased asthma risk (87). Several host factors, including respiratory allergy and virus-induced interferon responses, viral virulence factors, individual risk factors (e.g., young age, especially the first 6 months of life, small lung size and genetics), and environmental exposures (e.g., exposure to tobacco smoke, airway microbiome) modify the risk of virus-induced wheezing and promote more severe wheezing illnesses and the risk for progression to asthma $(86,88)$. The anti-RSV mAb palivizumab decreases the risk of severe RSV-induced illness and subsequent recurrent wheeze in prematurely born infants (89). Further understanding of the role of RSV in asthma pathogenesis may help develop vaccines against RSV as a way of asthma prevention.

Post infectious bronchiolitis obliterans caused by RSV. Bronchiolitis obliterans (BO) is a chronic and irreversible lung disease leading to the obstruction and/or obliteration of the small airways (90). Most cases of BO in children are post infectious (PIBO) and are mainly associated with adenovirus infections, although other viruses may also be 


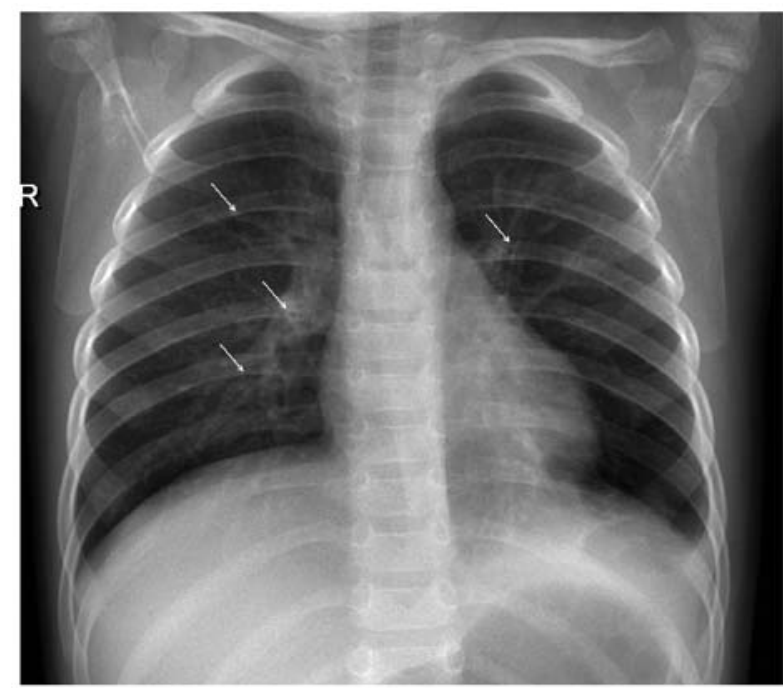

Figure 3. Chest radiograph of a 14-month-old girl admitted to hospital with RSV-positive ALRTI. There is hyperinflation of the lungs and presence of bronchial wall cuffing (arrows), without evidence of consolidation or effusion. RSV, respiratory syncytial virus; ALRTI, acute lower respiratory tract infection.

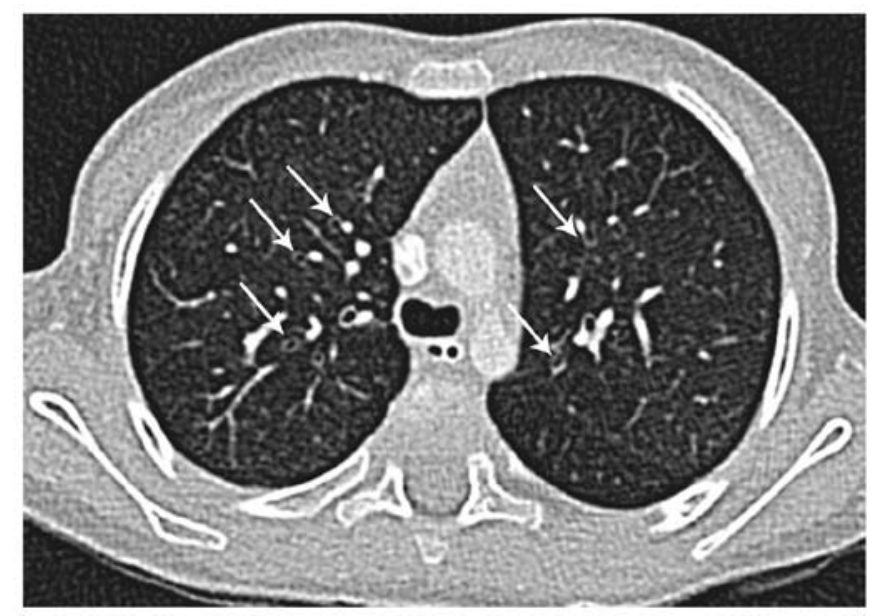

Figure 4. HRCT of the lungs of the same child as Fig. 3 using controlled ventilation technique, performed 4 months later due to recurrent bronchiolitis. Transverse thin-section CT scan through the upper lobes shows bilateral bronchial wall thickening (arrows) without evidence of bronchiectasis. HRCT, high-resolution computed tomography; CT, computed tomography.

implicated, including measles, influenza, parainfluenza and RSV (91-93). An extensive search of the current literature in the context of the workshop demonstrated that RSV is detected in children with PIBO with an incidence ranging from 4.3 to $30 \%$ (94-103); however, there are only a few reports of children with PIBO secondary to RSV as a single infection. This creates skepticism about the aetiological role of RSV in PIBO. Further research is required to investigate the potential impact of RSV co-infection in the severity and outcome of children with PIBO.

\section{Imaging in children with RSV infection}

Chest radiography and $R S V$-positive bronchiolitis. Although imaging cannot confirm the diagnosis of RSV infection, it

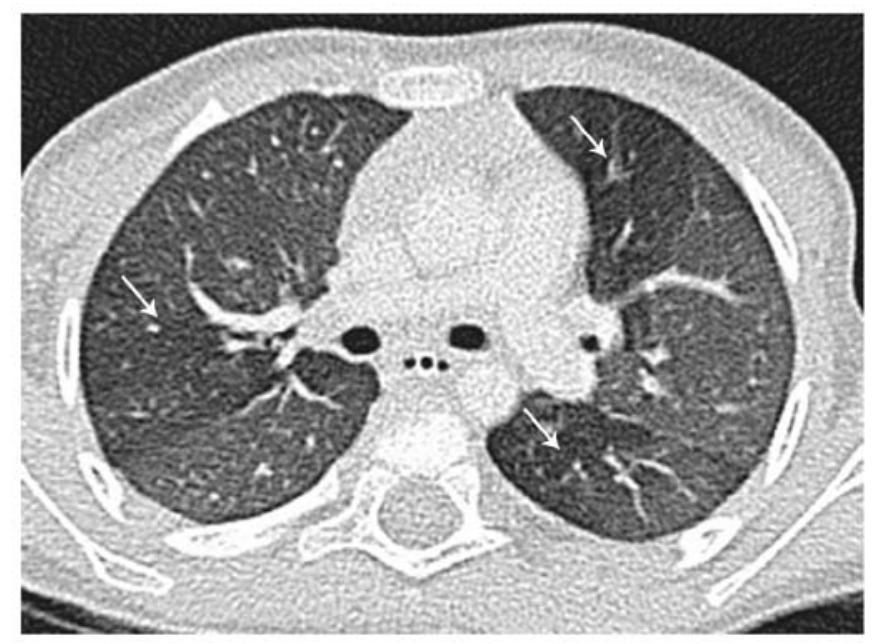

Figure 5. Same child; expiratory transverse thin-section CT scan through the same level as Fig. 4 reveals hyperlucent areas of air-trapping bilaterally (arrows). CT, computed tomography.

is important to identify the possible pattern of viral disease, in order to avoid unnecessary administration of antibiotic therapy and to predict possible late effects (Figs. 3-5) (104). The clinical syndrome of bronchiolitis is commonly diagnosed based on the patient's history and physical examination; chest radiography is not routinely recommended to reach the diagnosis due to recommended restriction of radiation exposure in the paediatric age group (104-106). Chest imaging, however, may be considered when a child with RSV infection and severe ALRTI is admitted to intensive care to better understand the extent of lung involvement and atelectasis, which is common in acute RSV infection (106). It is important to note that chest radiographs in children with RSV infection may be entirely normal or reveal non-specific findings, which are also encountered in other viral infections: most commonly, perihilar opacities and hyperinflation, atelectasis and rarely consolidation and bronchial cuffing or air-leak (107). Radiography is commonly obtained to rule out atelectasis and foreign body aspiration. Guidelines suggest performing a chest radiograph in the presence of significant respiratory distress or hospitalization (108). In newborns with RSV infection, the radiological pattern on chest radiography may be a predictor of clinical outcome (109). However, it is highlighted that chest radiographs should not be routinely performed in children with bronchiolitis to avoid radiation exposure (106). It is also important to emphasize that chest radiograph is not the right way to rule out bacterial infection (106); the correct diagnostic approach for bacterial or ventilator-associated pneumonia in children in the PICU is to perform respiratory culture or Matrix-assisted laser desorption ionization time-of-flight (MALDI-TOF) mass spectrometry from sputum/aspirate or bronchoalveolar lavage (BAL) specimens.

Chest CT and RSV-positive bronchiolitis. Several studies have revealed that standard radiological techniques, including computed tomography (CT), are frequently unable to distinguish between acute bronchiolitis changes caused by RSV vs. those caused by other respiratory viruses $(104,108)$. It is interesting that the radiographic findings, especially in 
high-resolution computed tomography (HRCT), reflect the histopathologic changes that RSV infection provokes: plugging or occlusion of the bronchiolar airway lumens by sloughed necrotic and irregular epithelium and exudate, combined with peri-bronchiolar infiltration and reaction with inflammatory cells and submucosal oedema. The infiltration is a combination of neutrophils entering the airway submucosa and epithelial cell debris in the airway lumens. These cellular accumulations are likely to result in acute obstruction of the distal airways, an outcome much more likely to occur in the extremely narrow bronchioles of infants. Because this is combined with the inherent loss of mechanical clearance of these small airways, it likely leads to increased spread of infection, augmented inflammation and clinical signs of wheezing/obstruction (110). Consistent with obstruction, the most common CT findings in RSV pneumonia include centrilobular nodules, ground-glass opacities, air-space consolidation, and peribronchial thickening (111). These findings have a bilateral, usually asymmetric, central and peripheral distribution. Up to $40 \%$ of children with bronchiolitis will develop further wheezing episodes in the first five years of life. In very severe or atypical cases, HRCT of the lungs may be required to assess the extent of bronchial thickening and remodeling, the development of brochiectases and air-trapping (105).

CNS imaging and RSV infection. RSV infection is not always restricted to the airways. Case reports have also described clinical pictures resembling viral encephalitis and/or encephalopathic syndromes with severe sequelae in isolated cases (112). The mechanism of the spread of the RSV infection to the CNS compartment remains unclear (112). Brain magnetic resonance imaging (MRI) in infants with CNS involvement has shown predominantly non-specific findings similar to those also encountered in other viral and/or limbic system encephalitides (113). In very rare instances, extra-pulmonary findings in RSV infection have also included acute necrotizing encephalopathy (ANE) and acute hepatic failure with encephalopathy (114). Clinicians should have a high suspicion of ANE in cases of children with a respiratory infection and acute neurological manifestations.

\section{Therapeutics of RSV infection}

Antivirals against RSV. Thus far, ribavirin is the only antiviral agent that has ever been licensed for the treatment of RSV infection (115). However, its efficacy is not proven and due to significant toxicity its use has been primarily restricted to severe cases in immunocompromised patients with severe RSV-positive ALRTI (116). Several other antiviral candidates have been developed since, but none have been licensed as yet. Types of molecules being tested include influenza antivirals, such as baloxavir, CC-42344, VIS410, immunoglobulin, hyperimmune plasma, MHAA4549A, pimodivir (JNJ-63623872), umifenovir, and HA minibinders, RSV antivirals including presatovir (GS-5806), ziresovir (AK0529), lumicitabine (ALS-008176), JNJ-53718678, JNJ-64417184, and EDP-938, broad spectrum antivirals such as favipiravir, VH244, remdesivir, and EIDD-1931/EIDD-2801, as well as host directed strategies including nitazoxanide, eritoran, and diltiazem (117-119). Novel molecules disrupt various stages of the virus life cycle, including cell entry, viral replication, and polymerization as well as after virus release through RSV neutralizing anti- or nanobodies (120).

The human challenge models. One method used occasionally in phase 2 clinical testing is human challenge models (115). This method was used in Phase 2 a clinical testing of the non-fusion inhibitor EDP-938 (ClinicalTrials.gov Identifier: NCT03691623). All participants were inoculated with a known strain of RSV and were then randomized to receive the medication or placebo. The advantage of this methodology is the removal of the variability in exposure with natural infection and the collection of samples at precise, known times after infection, which can aid with the understanding of the biological mechanisms of the infection and development of antiviral agents or vaccines $(121,122)$. Due to ethical and technical constraints, experimental studies are only undertaken in adults, but if a product is shown to be efficacious at this setting, a faster move to trials in paediatrics takes place than in traditional childhood trials.

$R S V$ therapeutics and personalized medicine. The current clinical data indicate that RSV disease dynamics may not be identical in all patients $(2,3,115,119)$. More research is needed to identify uniform clinical endpoints reflecting how patients function, thrive, and survive (US Food and Drug Administration) and to understand inter-individual differences in disease presentation, with the goal of ultimately selecting the right treatment for the right patient. A greater understanding of individual differences may ultimately lead to future personalized treatment strategies. Individualized approaches and a well-standardized methodology to assess disease severity at the time of enrolment, as well as during follow-up visits, will require integration of diagnostic, clinical and laboratory markers at the point of care (115). Individualized targeted treatment will constitute an important step in improving outcomes in patients with RSV infection while minimizing toxicity. A greater understanding of individual data in newly developed pharmaceutical agents against RSV will potentially lead to future personalized treatment regimens. Applying such co-ordinated diagnostic, clinical and research efforts constitutes an important step in advancing paediatric care, improving outcomes and limiting global RSV morbidity and mortality.

High-flow nasal cannula and RSV-positive bronchiolitis. Over the last decade, high-flow nasal cannula (HFNC) therapy has emerged as a new method to provide respiratory support in children with RSV-positive bronchiolitis (12,123-126). Its main advantages include its ease to set up and the fact that it is well tolerated, leading to better compliance, especially in comparison to other devices of non-invasive ventilation $(125,127)$. Initially, HFNC was trialed in infants with moderate to severe bronchiolitis admitted to PICUs, but nowadays its application has expanded to paediatric wards, even to emergency departments, in order to avoid a PICU admission $(127,128)$. Recent data have shown that it does not significantly reduce time on oxygen compared with standard therapy, suggesting that early use of HFNC does not modify the underlying disease process (129). However, the proportion of children who experi- 
ence treatment failure is lower in HFNC and many of those who experience treatment failure on standard therapy can be rescued by HFNC. Additional studies comparing HFNC with continuous positive airway pressure (CPAP) in the PICU setting led to the same conclusion $(130,131)$. Consequently, HFNC may reduce the need for intubation and invasive respiratory support, thus potentially lowering costs and adverse effects of mechanical ventilation, such as ventilator-induced lung injury, infections and exposure to sedatives. In addition to effectiveness, most studies have shown no adverse events with HFNC and have concluded that it is a relative safe method for use even in general wards or emergency departments (123). Few cases of pneumothorax have been reported, abdominal distension has been less significant compared with CPAP, and the majority of infants have been able to be fed orally or by nasogastric tube $(123,127)$.

Heliox and RSV-positive bronchiolitis. Since RSV-positive bronchiolitis is associated with airway obstruction and turbulent gas flow, its clinical course can be improved by Heliox, which facilitates gas flow through high-resistance airways (132-138). Heliox is a mixture of helium-oxygen, which can be administered by all modes of ventilation in spontaneously breathing patients by face mask, HFNC or CPAP, and can be adjusted to specific ventilators in intubated children. Current evidence suggests that the addition of Heliox may significantly reduce clinical scores evaluating respiratory distress and the respiratory rate, and may enhance $\mathrm{CO}_{2}$ elimination in the first hour after starting treatment in infants with acute refractory RSV bronchiolitis $(134,139)$. Recently, Seliem and Sultan (140) reported that Heliox results in improvement of oxygenation when used with high flow nasal cannula in infants with acute RSV bronchiolitis, during the initial phase of therapy. The combination of Heliox with CPAP also seems to be beneficial, as the application of CPAP may reduce the $\mathrm{fiO}_{2}$ needed in these infants. However, no benefit has been observed in terms of need for intubation and mechanical ventilation, length of treatment or PICU stay. In addition, its application in the emergency department does not change the discharge rate $(138,139)$. More clinical trials are needed to define the population that may respond to Heliox and its place in the therapeutic regimens of RSV bronchiolitis.

\section{Prevention of RSV infection}

Passive immunization and Palivizumab. The prevention of RSV morbidity and mortality remains a global healthcare priority $(115,141)$. According to the World Health Organization (WHO), the strategic focus for the prevention of RSV infection in children and adults includes the passive administration of immunoglobulins, as well as active immunization. Passive immunization is currently the only option available to infants less than 6 months of age, which can be achieved through administration of antibodies to the infant or through active immunization of the mother during pregnancy. Passive immunity wanes fast over time, thus, active immunization is the preferred approach for infants above six months of age, as well as older children and adults, including the elderly (141). To date, there is only one product available for prevention of
RSV infection, palivizumab, the monoclonal antibody (mAb) that has been shown to reduce hospital admission due to RSV infection in some high-risk infants by up to $80 \%$ (142). It is expensive and, thus, reserved for high risk infants, mainly in high income countries.

Active immunization against RSV: looking back to the past. While antibodies are costly and transitory in their effect, active vaccination would represent the most cost-effective approach for the prevention of RSV infections and their transmission to high-risk individuals $(115,141)$. Up to date, several vaccine candidates are in development, but none have reached licensure yet $(143,144)$. One of the main barriers for the development of RSV vaccines has been the fact that the majority of severe cases in infants occur within the first three months of life, i.e. at a time when active immunization is not really possible (145). Additional caution has been employed during vaccine design because of the failure of a historical vaccine [formalin inactivated RSV (FI-RSV)], which triggered a severe adverse effect, enhanced respiratory disease (ERD) (146). For more than 50 years live-attenuated vaccine approaches have been unsuccessful because of the difficulty in balancing immunogenicity and vaccine safety. It is worth noting that only live-attenuated vaccines have been tested for active infant immunization.

Active immunization against RSV: perspectives. Recent breakthroughs in determining the structure and antigenic content of the RSV fusion (F) glycoprotein has enhanced interest in vaccine development research $(115,141,147,148)$. The general approaches to vaccine development include engineered viruses that use knowledge of RSV gene function, naturally attenuated chimeric virus combining genes from RSV-related viruses, viral vectors encoding RSV surface antigens, and nucleic acid vaccines using plasmid DNA or messenger RNA encoding RSV antigens $(149,150)$. As of August 2019, 43 RSV vaccines were in development (151). Of these, 21 are in clinical trials in humans; 14 in Phase 1, five in Phase 2 and two (one just completed) in Phase 3. Twelve vaccines are in trials in children, four in pregnant women and 10 in older adults (some products are undergoing trials in more than one target population). Vaccine types under investigation include live-attenuated/chimeric, particle-based, subunit and recombinant vector vaccines. This highlights the variety and breadth of immunization types and different populations that are being investigated to find an answer to the 60-year-old problem of producing a safe and effective RSV prophylactic agent.

The ResVax. The most advanced candidate vaccine, ResVax, is an RSV fusion protein recombinant nanoparticle with aluminum phosphate as an adjuvant $(115,152,153)$. The new approach to develop this vaccine is based on engineering small particles that carry altered RSV proteins. The nanoparticles sensitize the immune system to the virus so that when a person comes in contact with it the immune system delivers a robust response. The Phase 3 clinical trial included more than 4,600 pregnant women examining the efficacy of prevention of RSV disease in infants through maternal immunization. Although the trial narrowly missed its primary end point 
of a reduction in medically attended RSV-positive ALRTI, it showed a $44 \%$ vaccine efficacy against RSV hospitalization, $25 \%$ efficacy against all respiratory hospitalizations and $39 \%$ efficacy against all-cause severe hypoxaemia (152). A possible route to licensure is currently being sought with the US Food and Drug Administration (FDA) and European licensing agencies, bringing hope of a vaccine that could save the lives of countless young infants worldwide.

\section{Acknowledgements}

We would like to thank the participants of the '5th Workshop on Paediatric Virology' (Sparta, Greece, October 12th, 2019) for their comments, corrections and feedback. We would also like to thank the organizing committee the '24th World Congress on Advances in Oncology' and the '24th International Symposium on Molecular Medicine' for the outstanding hosting of the workshop, as well as all members of the PVSG and the newly founded Institute of Paediatric Virology (IPV) based on the island of Euboea for their valuable contribution in the preparation of the manuscript.

\section{Funding}

No funding was received.

\section{Availability of data and materials}

Not applicable.

\section{Authors' contributions}

All authors (INM, SBD, BR, MT, GP, AP, EiK, CK, ElK, VA, PK, GPC and DAS) contributed to the conception and design of the study, wrote the original draft, edited and critically revised the manuscript, read and approved the final manuscript.

\section{Ethics approval and consent to participate}

Not applicable.

\section{Patient consent for publication}

Not applicable.

\section{Competing interests}

DAS is the Editor-in-Chief for the journal, but had no personal involvement in the reviewing process, or any influence in terms of adjudicating on the final decision, for this article. The other authors declare that they have no competing interests.

\section{References}

1. König IR, Fuchs O, Hansen G, von Mutius E and Kopp MV: What is precision medicine? Eur Respir J 50: 1700391, 2017.

2. Theodoridou M: RSV and precision medicine: Time for a more precise approach to diagnosis, treatment and prevention. Int J Mol Med 44: S32, 2019.

3. Barr R, Green CA, Sande CJ and Drysdale SB: Respiratory syncytial virus: Diagnosis, prevention and management. Ther Adv Infect Dis 6: 2049936119865798, 2019.
4. Li Y, Reeves RM, Wang X, Bassat Q, Brooks WA, Cohen C, Moore DP, Nunes M, Rath B, Campbell H, et al; RSV Global Epidemiology Network; RESCEU investigators: Global patterns in monthly activity of influenza virus, respiratory syncytial virus, parainfluenza virus, and metapneumovirus: A systematic analysis. Lancet Glob Health 7: e1031-e1045, 2019.

5. Alchikh M, Conrad T, Hoppe C, Ma X, Broberg E, Penttinen P, Reiche J, Biere B, Schweiger B and Rath B: Are we missing respiratory viral infections in infants and children? Comparison of a hospital-based quality management system with standard of care. Clin Microbiol Infect 25: 380.e9-380.e16, 2019.

6. Blount RE Jr, Morris JA and Savage RE: Recovery of cytopathogenic agent from chimpanzees with coryza. Proc Soc Exp Biol Med 92: 544-549, 1956.

7. Kapikian AZ, Morens DM and Fauci AS: In Memoriam: Robert M. Chanock, MD, 1924-2010. J Infect Dis 203: 3-5, 2011.

8. Gagliardi TB, Criado MF, Proença-Módena JL, Saranzo AM, Iwamoto MA, de Paula FE, Cardoso RS, Delcaro LS, Silva ML, Câmara AA, et al: Syncytia induction by clinical isolates of human respiratory syncytial virus A. Intervirology 60: 56-60, 2017.

9. Mammas IN and Spandidos DA: Updating taxonomy changes: RSV is now known as Orthopneumovirus. Int $\mathbf{J}$ Mol Med 44: S31, 2019.

10. ICTV Taxonomy history: Human orthopneumovirus. International Committee on Taxonomy of Viruses (ICTV), 2019. https://talk.ictvonline.org/taxonomy/.

11. Karampatsas K, Kong J and Cohen J: Bronchiolitis: An update on management and prophylaxis. Br J Hosp Med (Lond) 80: 278-284, 2019.

12. Cunningham S: Respiratory Support in Bronchiolitis: Trial Evidence. Am J Perinatol 35: 553-556, 2018.

13. Rath B, Maltezou HC, Papaevangelou V, PapagrigoriouTheodoridou MA, Alchikh M, Myles P and Schweiger B; PEDSIDEA Network: Partnering for enhanced digital surveillance of influenza-like disease and the effect of antivirals and vaccines (PEDSIDEA). Influenza Other Respir Viruses 13: 309-318, 2019.

14. Nair H, Brooks WA, Katz M, Roca A, Berkley JA, Madhi SA, Simmerman JM, Gordon A, Sato M, Howie S, et al: Global burden of respiratory infections due to seasonal influenza in young children: A systematic review and meta-analysis. Lancet 378: 1917-1930, 2011.

15. Zhou H, Thompson WW, Viboud CG, Ringholz CM, Cheng PY, Steiner C, Abedi GR, Anderson LJ, Brammer L and Shay DK: Hospitalizations associated with influenza and respiratory syncytial virus in the United States, 1993-2008. Clin Infect Dis 54: 1427-1436, 2012.

16. Homaira N, Mallitt KA, Oei JL, Hilder L, Bajuk B, Lui K, Rawlinson W, Snelling T and Jaffe A: Risk factors associated with RSV hospitalisation in the first 2 years of life, among different subgroups of children in NSW: A whole-of-population-based cohort study. BMJ Open 6: e011398, 2016.

17. Shi T, McAllister DA, O'Brien KL, Simoes EAF, Madhi SA, Gessner BD, Polack FP, Balsells E, Acacio S, Aguayo C, et al; RSV Global Epidemiology Network: Global, regional, and national disease burden estimates of acute lower respiratory infections due to respiratory syncytial virus in young children in 2015: A systematic review and modelling study. Lancet 390: 946-958, 2017.

18. Broberg EK, Waris M, Johansen K, Snacken R and Penttinen P; European Influenza Surveillance Network: Seasonality and geographical spread of respiratory syncytial virus epidemics in 15 European countries, 2010 to 2016. Euro Surveill 23: 23, 2018.

19. Boeckh M, Chien J, Daniel G, Daniels S, Dubovsky F, Cody Meissner H, McClellan M, Munoz FM, MurrayJS, Rath BA, et al: Advancing Drug Development for Respiratory Syncytial Virus. Duke, Washington, DC, 2016. https://healthpolicy.duke. edu/events/advancing-drug-development-respiratory-syncytial-virus. Accessed May 2, 2016.

20. European Centre for Disease Prevention and Control (ECDC): Technical Workshop: Burden of RSV disease in Europe. ECDC, Solna, 2015. https://ecdc.europa.eu/en/news-events/technicalworkshop-burden-rsv-disease-europe. Accessed January 3, 2018.

21. Alchikh M, Hoppe C, Conrad T, Schweiger B and Rath B: Are we missing respiratory viral infections in infants and children? Comparison of a hospital-based quality management system with standard of care. ESCMID 25: 380.e9-.380.e16, 2019.

22. Rath B and Penttinen P: Incidence, severity and impact of influenza: A joint meeting organised by the ISIRV Epidemiology Group and ECDC, Stockholm, 2019. Euro Surveill 24: 1900348, 2019. 
23. Ma X, Alchikh M, Conrad T, et al: Can we Distinguish Respiratory Viral Infections based on Clinical Symptoms? Lessons from a Pediatric Inception Cohort. In: Proceedings of the ASM2017 Microbe - American Society for Microbiology Conference, New Orleans, LA, 2017.

24. Tuttle R, Weick A, Schwarz WS, Chen X, Obermeier P, Seeber L, Tief F, Muehlhans S, Karsch K, Peiser C, et al: Evaluation of novel second-generation RSV and influenza rapid tests at the point of care. Diagn Microbiol Infect Dis 81: 171-176, 2015

25. Rath B: Vienna Vaccine Safety Initiative. Hum Vaccin Immunother 14: 1038-1041, 2018.

26. Rath B, Ali M, Codarini G, Elemuwa C, Khamesipour A, Maurer W, Mworozi E, Rundblad G, Varughese S and Kochhar S: Promoting evidence-based vaccine safety research and communication - the Vienna Vaccine Safety Initiative. J Trop Pediatr 58: $167-169,2012$

27. Rath B, Conrad T, Myles P, Alchikh M, Ma X, Hoppe C, Tief F, Chen X, Obermeier P, Kisler B, et al: Influenza and other respiratory viruses: Standardizing disease severity in surveillance and clinical trials. Expert Rev Anti Infect Ther 15: 545-568, 2017.

28. Rath B, Maltezou HC, Papaevangelou V, PapagrigoriouTheodoridou MA, Alchikh M, Myles P, Schweiger B, Asimaki H, Dimopoulou D, Hoppe C, et al; PEDSIDEA Network: Partnering for enhanced digital surveillance of influenza-like disease and the effect of antivirals and vaccines (PEDSIDEA). Influenza Other Respir Viruses 13: 309-318, 2019.

29. Rath B, Conrad T, Myles P, Alchikh M, Ma X, Hoppe C, Tief F, Chen X, Obermeier P, Kisler B and Schweiger B: The ViVI Disease Severity Score: Enabling Real-time Surveillance of Influenza Disease Severity for Multi-dimensional Mapping. In: Proceedings of 25th International Biodetection Technologies Conference 2017, Biodefense World Summit, Alexandria, VA, 2017.

30. Griffiths C, Drews SJ and Marchant DJ: Respiratory syncytial virus: Infection, detection, and new options for prevention and treatment. Clin Microbiol Rev 30: 277-319, 2017

31. Kozanidou E and Achtsidis V: RSV infection: Not for children only. Int J Mol Med 44: S32, 2019.

32. Falsey AR, Hennessey PA, Formica MA, Cox C and Walsh EE: Respiratory syncytial virus infection in elderly and high-risk adults. N Engl J Med 352: 1749-1759, 2005.

33. Branche AR and Falsey AR: Respiratory syncytial virus infection in older adults: An under-recognized problem. Drugs Aging 32: 261-269, 2015.

34. Blanco JCG, Boukhvalova MS, Morrison TG and Vogel SN A multifaceted approach to RSV vaccination. Hum Vaccin Immunother 14: 1734-1745, 2018.

35. Mammas IN and Spandidos DA: Overlap between RSV, influenza viruses and human metapneumovirus in childhood. Int $\mathbf{J}$ Mol Med 44: S43, 2019.

36. Koutsounaki E: The neonatal immune response to RSV infection: Advances in our understanding of viral and host cellular interactions. Int J Mol Med 44: S43, 2019.

37. Collins PL and Graham BS: Viral and host factors in human respiratory syncytial virus pathogenesis. J Virol 82: 2040-2055, 2008.

38. Scheltema NM, Kavelaars XM, Thorburn K, Hennus MP, van Woensel JB, van der Ent CK, Borghans JAM, Bont LJ and Drylewicz J: Potential impact of maternal vaccination on life-threatening respiratory syncytial virus infection during infancy. Vaccine 36: 4693-4700, 2018.

39. Mammas IN, Greenough A, Theodoridou M, Kramvis A Rusan M, Melidou A, Korovessi P, Papaioannou G, Papatheodoropoulou A, Koutsaftiki C, et al: Paediatric Virology and its interaction between basic science and clinical practice (Review). Int J Mol Med 41: 1165-1176, 2018.

40. Aranda SS and Polack FP: Prevention of pediatric respiratory syncytial virus lower respiratory tract illness: Perspectives for the next decade. Front Immunol 10: 1006, 2019.

41. Goritzka M, Durant LR, Pereira C, Salek-Ardakani S, Openshaw PJ and Johansson C: Alpha/beta interferon receptor signaling amplifies early proinflammatory cy tokine production in the lung during respiratory syncytial virus infection. J Virol 88: 6128-6136, 2014

42. Sun Y and López CB: The innate immune response to RSV: Advances in our understanding of critical viral and host factors. Vaccine 35: 481-488, 2017.

43. Caballero MT, Serra ME, Acosta PL, Marzec J, Gibbons L, Salim M, Rodriguez A, Reynaldi A, Garcia A, Bado D, et al: TLR4 genotype and environmental LPS mediate RSV bronchiolitis through Th2 polarization. J Clin Invest 125: 571-582, 2015.
44. Drysdale SB, Prendergast M, Alcazar M, Wilson T, Smith M, Zuckerman M, Broughton S, Rafferty GF, Johnston SL, Hodemaekers HM, et al: Genetic predisposition of RSV infection-related respiratory morbidity in preterm infants. Eur J Pediatr 173: 905-912, 2014

45. Restori KH, Srinivasa BT, Ward BJ and Fixman ED: Neonatal immunity, respiratory virus infections, and the development of asthma. Front Immunol 9: 1249, 2018.

46. Varricchi G, Harker J, Borriello F, Marone G, Durham SR and Shamji MH: T follicular helper (Tfh) cells in normal immune responses and in allergic disorders. Allergy 71: 1086-1094, 2016.

47. Blanken MO, Rovers MM, Molenaar JM, Winkler-Seinstra PL, Meijer A, Kimpen JL and Bont L; Dutch RSV Neonatal Network: Respiratory syncytial virus and recurrent wheeze in healthy preterm infants. N Engl J Med 368: 1791-1799, 2013.

48. Koutsaftiki C: MicroRNAs as potential bio-markers in children with RSV infection. Int J Mol Med 44: S32, 2019.

49. Głobińska A, Pawełczyk M and Kowalski ML: MicroRNAs and the immune response to respiratory virus infections. Expert Rev Clin Immunol 10: 963-971, 2014.

50. Rossi GA, Silvestri M and Colin AA: Respiratory syncytial virus infection of airway cells: Role of microRNAs. Pediatr Pulmonol 50: 727-732, 2015.

51. Kozomara A and Griffiths-Jones S: miRBase: Annotating high confidence microRNAs using deep sequencing data. Nucleic Acids Res 42 (D1): D68-D73, 2014.

52. Maltby S, Plank M, Tay HL, Collison A and Foster PS: Targeting microRNA function in respiratory diseases: Mini-review. Front Physiol 7: 21, 2016.

53. Thornburg NJ, Hayward SL and Crowe JE Jr: Respiratory syncytial virus regulates human microRNAs by using mechanisms involving beta interferon and NF- $\kappa$ B. MBio 3 : e00220-e12, 2012.

54. Feng S, Zeng D, Zheng J and Zhao D: MicroRNAs: Mediators and therapeutic targets to airway hyper reactivity after respiratory syncytial virus infection. Front Microbiol 9: 2177, 2018.

55. Anderson L, Jorquera PA and Tripp RA: MicroRNA profiling from RSV-infected biofluids, whole blood, and tissue samples. Methods Mol Biol 1442: 195-208, 2016

56. Thibault PA and Wilson JA: Targeting miRNAs to treat Hepatitis C Virus infections and liver pathology: Inhibiting the virus and altering the host. Pharmacol Res 75: 48-59, 2013.

57. Mammas IN and Spandidos DA: Thrombocytosis and RSV infection in hospitalized children with bronchiolitis. Int J Mol Med 44: S31, 2019.

58. Chiarello P, Magnolia M, Rubino M, Liguori SA and Miniero R: Thrombocytosis in children. Minerva Pediatr 63: 507-513, 2011.

59. Schafer AI: Thrombocytosis. N Engl J Med 350: 1211-1219, 2004

60. Mantadakis E, Tsalkidis A and Chatzimichael A: Thrombocytosis in childhood. Indian Pediatr 45: 669-677, 2008.

61. Shin J, Lee DH, Jung N, Choi HJ and Shim YJ: A cross-sectional retrospective study to analyze the underlying causes and clinical characteristics of children with reactive thrombocytosis at a Korean tertiary medical center. Blood Res 53: 233-239, 2018.

62. Kubota M, Maeda H, Yoshimoto J, Kobayashi K, Usami I and Yamaoka K: Thrombocytosis at an early stage of respiratory tract viral infection. Acta Paediatr 94: 364-366, 2005.

63. Bilavsky E, Yarden-Bilavsky H, Shouval DS, Fisch N, Garty BZ, Ashkenazi S and Amir J: Respiratory syncytial virus-positive bronchiolitis in hospitalized infants is associated with thrombocytosis. Isr Med Assoc J 12: 39-41, 2010.

64. Zheng SY, Xiao QY, Xie XH, Deng Y, Ren L, Tian DY, Luo ZX, Luo J, Fu Z, Huang AL, et al: Association between secondary thrombocytosis and viral respiratory tract infections in children. Sci Rep 6: 22964, 2016.

65. Mammas I, Koutsaftiki C, Tapaki-Papadopoulou G and Myriokefalitakis N: Respiratory syncytial virus (RSV) bronchiolitis and excessive thrombocytosis. Acta Paediatr 99: 489-490, 2010.

66. Ng KF, Tan KK, Sam ZH, Ting GS and Gan WY: Epidemiology, clinical characteristics, laboratory findings and severity of respiratory syncytial virus acute lower respiratory infection in Malaysian children, 2008-2013. J Paediatr Child Health 53: 399-407, 2017.

67. Vlacha V and Feketea G: Thrombocytosis in pediatric patients is associated with severe lower respiratory tract inflammation. Arch Med Res 37: 755-759, 2006.

68. Haidopoulou K, Goutaki M, Lemonaki M, Kavga M and Papa A: Reactive thrombocytosis in children with viral respiratory tract infections. Minerva Pediatr 63: 257-262, 2011. 
69. Indolfi G, Catania P, Bartolini E, Azzari C, Massai C, Poggi GM, De Martino $M$ and Resti M: Incidence and clinical significance of reactive thrombocytosis in children aged 1 to 24 months, hospitalized for community-acquired infections. Platelets 19: 409-414, 2008.

70. Denton A and Davis P: Extreme thrombocytosis in admissions to paediatric intensive care: No requirement for treatment. Arch Dis Child 92: 515-516, 2007.

71. Korovessi P: RSV bronchiolitis and paediatric asthma. Int J Mol Med 44: S42, 2019.

72. Kabego L and de Beer C: Association between respiratory syncytial virus infection in infancy and subsequent asthma: A meta-analysis of observational studies. JSM Allergy Asthma 2: 1009, 2017.

73. Régnier SA and Huels J: Association between respiratory syncytial virus hospitalizations in infants and respiratory sequelae: Systematic review and meta-analysis. Pediatr Infect Dis J 32: 820-826, 2013.

74. Jartti T, Smits HH, Bønnelykke K, Bircan O, Elenius V, Konradsen JR, Maggina P, Makrinioti H, Stokholm J, Hedlin G, et al; EAACI Task Force on Clinical Practice Recommendations on Preschool Wheeze: Bronchiolitis needs a revisit: Distinguishing between virus entities and their treatments. Allergy 74: 40-52, 2019.

75. Fauroux B, Simões EAF, Checchia PA, Paes B, Figueras-Aloy J, Manzoni P, Bont L and Carbonell-Estrany X: The burden and long-term respiratory morbidity associated with respiratory syncytial virus infection in early childhood. Infect Dis Ther 6: 173-197, 2017.

76. Homaira N, Briggs N, Pardy C, Hanly M, Oei JL, Hilder L, Bajuk B, Lui K, Rawlinson W, Snelling T, et al: Association between respiratory syncytial viral disease and the subsequent risk of the first episode of severe asthma in different subgroups of high-risk Australian children: A whole-of-population-based cohort study. BMJ Open 7: e017936, 2017.

77. Thomsen SF, van der Sluis S, Stensballe LG, Posthuma D, Skytthe A, Kyvik KO, Duffy DL, Backer V and Bisgaard H: Exploring the association between severe respiratory syncytial virus infection and asthma: A registry-based twin study. Am J Respir Crit Care Med 179: 1091-1097, 2009.

78. Mochizuki H, Kusuda S, Okada K, Yoshihara S, Furuya H, Simões EAF, Asanuma $H$, Yoshida $H$, Katayose $M$, Imamura $\mathrm{T}$, et al; Scientific Committee for Elucidation of Infantile Asthma: Palivizumab prophylaxis in preterm infants and subsequent recurrent wheezing. Six-year follow-up study. Am J Respir Crit Care Med 196: 29-38, 2017.

79. Scheltema NM, Nibbelke EE, Pouw J, Blanken MO, Rovers MM, Naaktgeboren CA, Mazur NI, Wildenbeest JG, van der Ent CK and Bont LJ: Respiratory syncytial virus prevention and asthma in healthy preterm infants: A randomised controlled trial. Lancet Respir Med 6: 257-264, 2018

80. Carbonell-Estrany X, Pérez-Yarza EG, García LS, Guzmán Cabañas JM, Bòria EV and Atienza BB; IRIS (Infección Respiratoria Infantil por Virus Respiratorio Sincitial) Study Group: Long-term burden and respiratory effects of respiratory syncytial virus hospitalization in preterm infants - The SPRING Study. PLoS One 10: e0125422, 2015.

81. Lukkarinen M, Koistinen A, Turunen R, Lehtinen P, Vuorinen T and Jartti T: Rhinovirus-induced first wheezing episode predicts atopic but not nonatopic asthma at school age. J Allergy Clin Immunol 140: 988-995, 2017.

82. Rubner FJ, Jackson DJ, Evans MD, Gangnon RE, Tisler CJ, Pappas TE, Gern JE and Lemanske RF Jr: Early life rhinovirus wheezing, allergic sensitization, and asthma risk at adolescence. J Allergy Clin Immunol 139: 501-507, 2017.

83. Koutsaftiki C: Predicting asthma following RSV-positive bronchiolitis in early childhood. Int J Mol Med 44: S31, 2019.

84. Drysdale SB, Alcazar-Paris M, Wilson T,Smith M,Zuckerman M, Peacock JL, Johnston SL and Greenough A: Viral lower respiratory tract infections and preterm infants' healthcare utilisation. Eur J Pediatr 174: 209-215, 2015.

85. Drysdale SB, Milner AD and Greenough A: Respiratory syncytial virus infection and chronic respiratory morbidity - is there a functional or genetic predisposition? Acta Paediatr 101: 1114-1120, 2012.

86. Gern JE: Viral respiratory infection and the link to asthma. Pediatr Infect Dis J 27 (Suppl): S97-S103, 2008.

87. Bacharier LB, Cohen R, Schweiger T, Yin-Declue H, Christie C, Zheng J, Schechtman KB, Strunk RC and Castro M: Determinants of asthma after severe respiratory syncytial virus bronchiolitis. J Allergy Clin Immunol 130: 91-100.e3, 2012.
88.Lu S, Hartert TV, Everard ML, Giezek H, Nelsen L, Mehta A, Patel H, Knorr B and Reiss TF: Predictors of asthma following severe respiratory syncytial virus (RSV) bronchiolitis in early childhood. Pediatr Pulmonol 51: 1382-1392, 2016.

89. Jartti T and Gern JE: Role of viral infections in the development and exacerbation of asthma in children. J Allergy Clin Immunol 140: 895-906, 2017.

90. Grivas G, Lymperatou C and Korovessi P: Post infectious bronchiolitis obliterans caused by respiratory syncytial virus (RSV) in children. Int J Mol Med 44: S42, 2019.

91.Kavaliunaite E and Aurora P: Diagnosing and managing bronchiolitis obliterans in children. Expert Rev Respir Med 13: 481-488, 2019.

92. Champs NS, Lasmar LM, Camargos PA, Marguet C, Fischer GB and Mocelin HT: Post-infectious bronchiolitis obliterans in children. J Pediatr (Rio J) 87: 187-198, 2011.

93. Rodríguez DA, Rodríguez-Martínez CE, Cárdenas AC, Quilaguy IE, Mayorga LY, Falla LM and Nino G: Predictors of severity and mortality in children hospitalized with respiratory syncytial virus infection in a tropical region. Pediatr Pulmonol 49: 269-276, 2014.

94. Wu XY, Luo ZX, Fu Z, Liu EM, Luo J and He L: Clinical analysis of 28 cases of bronchiolitis obliterans. Zhongguo Dang Dai Er Ke Za Zhi 15: 845-849, 2013 (In Chinese).

95. Yanagisawa J, Shiraishi T, Okamatsu Y and Iwasaki A: Successful lung volume reduction surgery in an infant with emphysema after respiratory syncytial virus-induced obliterative bronchiolitis. J Thorac Cardiovasc Surg 145: e47-e49, 2013.

96. Chen DH, Lin YN, Lan SL, Pan XA, Zeng QS, He ZT, Liang M, Zhang BY, Wu SZ, Xu JX, et al: Clinical characteristics of bronchiolitis obliterans in pediatric patients. Zhonghua $\mathrm{Er} \mathrm{Ke}$ Za Zhi 50: 98-102, 2012 (In Chinese).

97. Giovannini-Chami L, Khirani S, Thouvenin G, Ramirez A and Fauroux B: Work of breathing to optimize noninvasive ventilation in bronchiolitis obliterans. Intensive Care Med 38: 722-724, 2012

98. Sardón O, Pérez-Yarza EG, Aldasoro A, Corcuera P, Mintegui J and Korta J: Bronchiolitis obliterans: Outcome in the medium term. An Pediatr (Barc) 76: 58-64, 2012 (In Spanish).

99. Wang W, Shen KL and Zeng JJ: Clinical studies of children with bronchiolitis obliterans. Zhonghua Er Ke Za Zhi 46: 732-738, 2008 (In Chinese).

100. Lobo AL, Guardiano M, Nunes T, Azevedo I and Vaz LG: Pos-infectious bronchiolitis obliterans in children. Rev Port Pneumol 13: 495-509, 2007.

101. Hirschheimer M, Silva PS, Giudici R, Carrilho M, Mauad T and Ishida M: Simultaneous viral infection and childhood bronchiolitis obliterans. Braz J Infect Dis 6: 146-148, 2002.

102. Massie R and Armstrong D: Bronchiectasis and bronchiolitis obliterans post respiratory syncytial virus infection: Think again. J Paediatr Child Health 35: 497-498, 1999.

103. Yalçin E, Doğru D, Haliloğlu M, Ozçelik U, Kiper N and Göçmen A: Postinfectious bronchiolitis obliterans in children: Clinical and radiological profile and prognostic factors. Respiration 70: 371-375, 2003.

104.Papaioannou G: Imaging in children with RSV infection. Int J Mol Med 44: S30, 2019.

105. Dawson-Caswell M and Muncie HL Jr: Respiratory syncytial virus infection in children. Am Fam Physician 83: 141-146, 2011

106. National Institute for Health and Care Excellence (NICE) Bronchiolitis in children: diagnosis and management, NICE guideline [NG9]. https://www.nice.org.uk/guidance/ng9. Accessed June 1,2015.

107. Kern S, Uhl M, Berner R, Schwoerer T and Langer M: Respiratory syncytial virus infection of the lower respiratory tract: Radiological findings in 108 children. Eur Radiol 11: 2581-2584, 2001.

108. Hilmes MA, Daniel Dunnavant F, Singh SP, Ellis WD, Payne DC, Zhu Y, Griffin MR, Edwards KM and Williams JV: Chest radiographic features of human metapneumovirus infection in pediatric patients. Pediatr Radiol 47: 1745-1750, 2017.

109. Alkan Ozdemir S, Ozer EA, Pekcevik Y, Ilhan O and Sutcuoglu S: Is radiological appearance of lower respiratory tract infection due to respiratory syncytial virus a predictor of clinical outcome? J Matern Fetal Neonatal Med 28: 1660-1663, 2015.

110. Pickles R and DeVincenzo J: PSV and its propensity for causing bronchioloitis. J Pathol 235: 266-267, 2015.

111. Franquet T: Imaging of pulmonary viral pneumonia. Radiology 260: 18-39, 2011. 
112. Xu L, Gao H, Zeng J, Liu J, Lu C, Guan X, Qian S and Xie Z: A fatal case associated with respiratory syncytial virus infection in a young child. BMC Infect Dis 18: 217, 2018.

113. Park A, Suh SI, Son GR, Lee YH, Seo HS, Eun BL, Lee NJ and Seol HY: Respiratory syncytial virus-related encephalitis: Magnetic resonance imaging findings with diffusion-weighted study. Neuroradiology 56: 163-168, 2014.

114. Al-Maskari N, Mohsin J, Al-Maani A, Al-Macki N and Al-Ismaili S: Atypical presentations of respiratory syncytial virus infection: Case series. Sultan Qaboos Univ Med J 16: e86-e91, 2016.

115. Drysdale SB: Management of RSV infection in children: New advances and challenges. Int J Mol Med 44: S26, 2019.

116. Krilov LR: Safety issues related to the administration of ribavirin. Pediatr Infect Dis J 21: 479-481, 2002.

117. Behzadi MA and Leyva-Grado VH: Overview of current therapeutics and novel candidates against influenza, respiratory syncytial virus, and Middle East respiratory syndrome coronavirus infections. Front Microbiol 10: 1327, 2019.

118. Xing Y and Proesmans M: New therapies for acute RSV infections: Where are we? Eur J Pediatr 178: 131-138, 2019.

119. Beigel JH, Nam HH, Adams PL, Krafft A, Ince WL, El-Kamary SS and Sims AC: Advances in respiratory virus therapeutics - A meeting report from the 6th isirv Antiviral Group conference. Antiviral Res 167: 45-67, 2019.

120. Nicholson EG and Munoz FM: A review of therapeutics in clinical development for respiratory syncytial virus and influenza in children. Clin Ther 40: 1268-1281, 2018.

121. Sherman AC, Mehta A, Dickert NW, Anderson EJ and Rouphael N: The future of flu: A review of the human challenge model and systems biology for advancement of influenza vaccinology. Front Cell Infect Microbiol 9: 107, 2019.

122. Jozwik A, Habibi MS, Paras A, Zhu J, Guvenel A, Dhariwal J, Almond M, Wong EHC, Sykes A, Maybeno M, et al: RSV-specific airway resident memory $\mathrm{CD} 8+\mathrm{T}$ cells and differential disease severity after experimental human infection. Nat Commun 6 : $10224,2015$.

123.Papatheodoropoulou A: High-flow warm humidified oxygen via nasal cannula and RSV-positive bronchiolitis among children admitted to PICU. Int J Mol Med 44: S30, 2019.

124. Beggs S, Wong ZH, Kaul S, Ogden KJ and Walters JA: High-flow nasal cannula therapy for infants with bronchiolitis. Cochrane Database Syst Rev 2014: CD009609, 2014.

125. Franklin D, Dalziel S, Schlapbach LJ, Babl FE, Oakley E, Craig SS, Furyk JS, Neutze J, Sinn K, Whitty JA, et al; PARIS and PREDICT: Early high flow nasal cannula therapy in bronchiolitis, a prospective randomised control trial (protocol): A Paediatric Acute Respiratory Intervention Study (PARIS). BMC Pediatr 15: 183, 2015

126. van Miert C, Fernandes RM, Eccleson H, Bedson E, Lane S, Peak M, Thorburn K, Compton V, Woolfall K, Lacy D, et al: Non-invasive ventilation for the management of children with bronchiolitis (NOVEMBR): A feasibility study and core outcome set development protocol. Trials 19: 627, 2018.

127. Kepreotes E, Whitehead B, Attia J, Oldmeadow C, Collison A, Searles A, Goddard B, Hilton J, Lee M and Mattes J: High-flow warm humidified oxygen versus standard low-flow nasal cannula oxygen for moderate bronchiolitis (HFWHO RCT): An open, phase 4, randomised controlled trial. Lancet 389: 930-939, 2017.

128. Franklin D, Babl FE, Schlapbach LJ, Oakley E, Craig S, Neutze J, Furyk J, Fraser JF, Jones M, Whitty JA, et al: A randomized trial of high-flow oxygen therapy in infants with bronchiolitis. $\mathrm{N}$ Engl J Med 378: 1121-1131, 2018.

129. Goh CT, Kirby LJ, Schell DN and Egan JR: Humidified high-flow nasal cannula oxygen in bronchiolitis reduces need for invasive ventilation but not intensive care admission. J Paediatr Child Health 53: 897-902, 2017.

130. Clayton JA, McKee B, Slain KN, Rotta AT and Shein SL: Outcomes of children with bronchiolitis treated with high-flow nasal cannula or noninvasive positive pressure ventilation. Pediatr Crit Care Med 20: 128-135, 2019.

131. Milési C, Essouri S, Pouyau R, Liet JM, Afanetti M, Portefaix A, Baleine J, Durand S, Combes C, Douillard A, et al; Groupe Francophone de Réanimation et d'Urgences Pédiatriques (GFRUP): High flow nasal cannula (HFNC) versus nasal continuous positive airway pressure (nCPAP) for the initial respiratory management of acute viral bronchiolitis in young infants: A multicenter randomized controlled trial (TRAMONTANE study). Intensive Care Med 43: 209-216, 2017.
132.Papatheodoropoulou A: Heliox and RSV-positive bronchiolitis Int J Mol Med 44: S32, 2019.

133. Hess DR, Fink JB, Venkataraman ST, Kim IK, Myers TR and Tano BD: The history and physics of heliox. Respir Care 51: 608-612, 2006.

134. Nascimento MS, Santos É and Prado CD: Helium-oxygen mixture: Clinical applicability in an intensive care unit. Einstein (Sao Paulo) 16: eAO4199, 2018.

135. Barach AL: The therapeutic use of helium. JAMA 107: 1273-1280, 1936.

136. Moraa I, Sturman N, McGuire TM and van Driel ML: Heliox for croup in children. Cochrane Database Syst Rev 10: CD006822, 2018.

137. Morgan SE, Vukin K, Mosakowski S, Solano P, Stanton L, Lester L, Lavani R, Hall JB and Tung A: Use of heliox delivered via high-flow nasal cannula to treat an infant with coronavirus-related respiratory infection and severe acute air-flow obstruction. Respir Care 59: e166-e170, 2014.

138. Martinón-Torres F: Noninvasive ventilation with helium-oxygen in children. J Crit Care 27: 220.e1-220.e9, 2012

139. Liet JM, Ducruet T, Gupta V and Cambonie G: Heliox inhalation therapy for bronchiolitis in infants. Cochrane Database Syst Rev (9): CD006915, 2015

140. Seliem W and Sultan AM: Heliox delivered by high flow nasal cannula improves oxygenation in infants with respiratory syncytial virus acute bronchiolitis. J Pediatr (Rio J) 94: 56-61, 2018.

141. Theodoridou M: Prevention of RSV infection: What is new with the vaccines? J Mol Med (Berl) 44: S29, 2019.

142. Wang D, Cummins C, Bayliss S, Sandercock J and Burls A: Immunoprophylaxis against respiratory syncytial virus (RSV) with palivizumab in children: A systematic review and economic evaluation. Health Technol Assess 12: iii, ix-x, 1-86, 2008.

143. Modjarrad K, Giersing B, Kaslow DC, Smith PG and Moorthy VS; WHO RSV Vaccine Consultation Expert Group: WHO consultation on Respiratory Syncytial Virus Vaccine Development Report from a World Health Organization Meeting held on 23-24 March 2015. Vaccine 34: 190-197, 2016.

144. Nair H, Nokes DJ, Gessner BD, Dherani M, Madhi SA, Singleton RJ, O'Brien KL, Roca A, Wright PF, Bruce N, et al: Global burden of acute lower respiratory infections due to respiratory syncytial virus in young children: A systematic review and meta-analysis. Lancet 375: 1545-1555, 2010.

145. Gerretsen HE and Sande CJ: Development of respiratory syncytial virus (RSV) vaccines for infants. J Infect 74 (Suppl 1): S143-S146, 2017.

146. Prince GA, Jenson AB, Hemming VG, Murphy BR, Walsh EE, Horswood RL and Chanock RM: Enhancement of respiratory syncytial virus pulmonary pathology in cotton rats by prior intramuscular inoculation of formalin-inactivated virus. J Virol 57: 721-728, 1986.

147. Graham BS: Vaccine development for respiratory syncytial virus. Curr Opin Virol 23: 107-112, 2017.

148. Graham BS: Vaccines against respiratory syncytial virus: The time has finally come. Vaccine 34: 3535-3541, 2016

149. Widjojoatmodjo MN, Bogaert L, Meek B, Zahn R, Vellinga J, Custers J, Serroyen J, Radošević K and Schuitemaker H: Recombinant low-seroprevalent adenoviral vectors Ad26 and Ad35 expressing the respiratory syncytial virus (RSV) fusion protein induce protective immunity against RSV infection in cotton rats. Vaccine 33: 5406-5414, 2015.

150.Pardi $\mathrm{N}$ and Weissman D: Nucleoside modified mRNA vaccines for infections diseases. Methods Mol Biol 1499: 109-121, 2017.

151. PATH: RSV vaccine mAb snapshot. https://path.azureedge.net/ media/documents/RSV-snapshot-2019_08_28_High_Resolution_ PDF.pdf. Accessed August 28, 2019.

152. Novavax: Prepare ${ }^{\mathrm{TM}}$ Trial Topline Results. https://novavax. com/2019_02_27_ResVax_Draft.pdf. Accessed February 28, 2019.

153.Patrick M: Will the ResVax vaccine be key revenue driver for Novavax. Market Realist, 2019. https://marketrealist com/2019/05/will-the-resvax-vaccine-be-key-revenue-driverfor-novavax/. Accessed May 6, 2019.

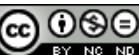

This work is licensed under a Creative Commons Attribution-NonCommercial-NoDerivatives 4.0 International (CC BY-NC-ND 4.0) License. 